\section{Nasal and instrument preparation prior to rigid and flexible nasendoscopy: a systematic review \\ J Laryngol Otol 2008;122:1024-8}

Dear Sirs

We read with great interest the review by Nankivell and Pothier ${ }^{1}$ on topical preparations for rigid and flexible nasendoscopy. The studies on this topic are of relatively small size with low statistical power (when quoted), and methodological differences render cumulative analysis difficult. It is therefore appropriate that descriptive summaries of these studies are presented, rather than statistical metanalysis.

However, given the inconsistency of the results of these studies' with regard to the effect of topical vasoconstrictors, it may be imprudent to infer that lidocaine and vasoconstrictors, individually or combined, have no more effect than placebo on patient discomfort (as stated in Nankivell and Pothier's discussion section). Whereas no statistical difference between local anaesthesia alone vs placebo or no treatment is a consistent theme, Sadek et $a l^{2}$ reported that vasoconstriction reduced the unpleasantness of flexible nasendoscopy $(p=0.022)$. Supporting this, Jonas et $a l^{3}$ found no benefit from the addition of a local anaesthetic (lidocaine) to a decongestant (oxymetazoline). However, in contrast, Leder et al. ${ }^{4}$ found no difference between tetracaine alone, adrenaline alone, saline alone and nothing. Interestingly, Pothier et al. ${ }^{5}$ reported that performing rigid nasendoscopy 10 minutes as opposed to one minute after co-phenylcaine application produces less discomfort, less pain and easier insertion. If local anaesthesia is accepted as having no significant effect compared to placebo or no nasal preparation, then this effect of cophenylcaine, in the context of a review of the topic, could have been attributable to the vasoconstrictor properties. The additional contribution by Douglas et al. ${ }^{6}$ that co-phenylcaine compared to lignocaine provided a better view for rigid endoscopy (though no difference in discomfort), suggests that vasoconstrictors may have a clinical benefit in preparing the nose for nasendoscopy.

We suggest that the present literature is inconclusive regarding the benefit from vasoconstriction.

R P De Freitas

B C Hannah

ENT Department,

Craigavon Area Hospital,

Northern Ireland, UK.

\section{References}

1 Nankivell PC, Pothier DD. Nasal and instrument preparation prior to rigid and flexible nasendoscopy: a systematic review. J Laryngol Otol 2008;122:1024-8

2 Sadek SA, Scott A, White AP, Wilson PS, Carlin WV. The efficacy of topical anaesthesia in flexible nasendoscopy: a double-blind randomised controlled trial. Clin Otolaryngol Allied Sci 2001;26:25-8

3 Jonas NE, Visser MF, Oomen A, Albertyn R, van Dijk M, Prescott CA. Is topical local anaesthesia necessary when performing paediatric flexible nasendoscopy? A double blind randomized controlled trial. Int J Pediatr Otorhinolaryngol 2007;71:1687-92

4 Leder SB, Ross DA, Briskin KB, Sasaki CT. A prospective, double-blind, randomized study on the use of a topical anesthetic, vasconstrictor, and placebo during transnasal flexible fiberoptic endoscopy. J Speech Lang Hear Res 1997;40: 1352-7

5 Pothier DD, Hall CE, Nankivell P. Timing of co-phenylcaine administration before rigid nasendoscopy: a randomized, controlled trial. J Laryngol Otol 2007;121:228-30

6 Douglas R, Hawke L, Wormald PJ. Topical anaesthesia before nasendoscopy: a randomized controlled trial of co-phenylcaine compared with lignocaine. Clin Otolaryngol Allied Sci 2006;31:33-5

\section{Authors' reply}

Dear Sirs

We thank De Freitas and Hannah for their interest in our article. ${ }^{1}$ However, we believe that a few points require clarification.

Firstly, whilst we agree that Sadek et al. $^{2}$ did show a reduction in unpleasantness when using a vasoconstrictor, the statement that Jonas et $a l^{3}$ support this view is incorrect. The latter study compared only vasoconstrictor and local anaesthetic (finding no difference) and, as the study included no control group using no nasal preparation, it is not possible to conclude that use of a vasoconstrictor resulted in less unpleasantness. Indeed, as De Freitas and Hannah rightly point out, Leder and colleagues' four-arm trial $^{4}$ found no difference between anaesthetic, vasoconstrictor, placebo and nothing.

De Freitas and Hannah state that, "[i]f local anaesthesia is accepted as having no significant effect compared to placebo...'; we believe this statement to be misleading. The study they quote (Pothier et al. $)^{5}$ assessed the timing of preparation and its effect on the ease of nasendoscopy and the quality of the viewing image. This study's finding, that 10 minutes was superior to one minute, reflects the time the preparation (containing anaesthetic as well as vasoconstrictor) was in contact with the nasal mucosa, and therefore is the only valid conclusion that can be drawn. Furthermore, this study used rigid nasendoscopy, meaning that results cannot be extrapolated to or compared with those of flexible nasendoscopy.

Finally, we agree with De Freitas and Hannah's comment that the literature is inconclusive regarding topical preparations, due to the lack of high quality data; it remains to be seen whether such data will emerge in the future.

\section{P C Nankivell}

D D Pothier*

From the Institute of Head and

Neck Studies and Education,

University Hospital Coventry and Warwick, Coventry, and the *Department of Otolaryngology, Southmead Hospital, Bristol, UK

First published online 20 May 2009. 


\section{References}

1 Nankivell PC, Pothier DD. Nasal and instrument preparation prior to rigid and flexible nasendoscopy: a systematic review. J Laryngol Otol 2008;122:1024-8

2 Sadek SA, Scott A, White AP, Wilson PS, Carlin WV. The efficacy of topical anaesthesia in flexible nasendoscopy: a double-blind randomised controlled trial. Clin Otolaryngol Allied Sci 2001;26:25-8

3 Jonas NE, Visser MF, Oomen A, Albertyn R, van Dijk M, Prescott CA. Is topical local anaesthesia necessary when performing paediatric flexible nasendoscopy? A double blind randomized controlled trial. Int J Pediatr Otorhinolaryngol 2007;71:1687-92

4 Leder SB, Ross DA, Briskin KB, Sasaki CT. A prospective, double-blind, randomized study on the use of a topical anesthetic, vasconstrictor, and placebo during transnasal flexible fiberoptic endoscopy. J Speech Lang Hear Res 1997;40: 1352-7

5 Pothier DD, Hall CE, Nankivell P. Timing of co-phenylcaine administration before rigid nasendoscopy: a randomized, controlled trial. J Laryngol Otol 2007;121: $228-30$

\section{The Journal of Laryngology \& Otology}

\section{JLO WEB EDITOR}

The board of JLO (1984) Ltd seek to appoint a Web Editor to manage and develop the website of The Journal of Laryngology and Otology (www.jlo.co.uk)

The Journal of Laryngology and Otology is an international general otolaryngology journal published on behalf of JLO (1984) Ltd by Cambridge University Press

The Editor of the JLO website will be responsible for editing and updating content as well as leading improvements and developments to the website. This position will ensure the site is up to date in terms of content, functionality and commercial viability, and drive a substantial increase in the number of visitors to make it the leading site in its field

The Web Editor must have previous experience in managing websites, including editing and uploading video content, and have writing and editing experience with content management systems

For further details and a job description please contact:

Rosamund Greensted

Managing Editor

Email: j.I.o@btconnect.com 